\title{
A Flexible Photoactive Titanium Metal-Organic Framework Based on a $\left[\mathrm{Til}_{3}\left(\mu_{3}-\mathrm{O}\right)(\mathrm{O})_{2}(\mathrm{COO})_{6}\right]$ Cluster**
}

\author{
Bart Bueken, Frederik Vermoortele, Danny E. P. Vanpoucke, Helge Reinsch, Chih-Chin Tsou, \\ Pieterjan Valvekens, Trees De Baerdemaeker, Rob Ameloot, Christine E. A. Kirschhock, Veronique \\ Van Speybroeck, James M. Mayer and Dirk De Vos*
}

\begin{abstract}
The synthesis of titanium-carboxylate metal-organic frameworks (MOFs) is hampered by the high reactivity of the commonly employed alkoxide precursors. Here, we present an innovative approach to Ti-based MOFs using titanocene dichloride to synthesize COK-69, the first breathing Ti-MOF, which is built up of trans-1,4-cyclohexanedicarboxylate linkers and an unprecedented $\left[\mathrm{TiV}_{3}\left(\mu_{3}-\mathrm{O}\right)(\mathrm{O})_{2}(\mathrm{COO})_{6}\right]$ cluster. The photoactive properties of COK-69 were investigated in-depth by proton-coupled electron transfer experiments, which revealed that up to one $\mathrm{Ti}^{\mathrm{iv}}$ per cluster can be photoreduced to Till', while preserving the structural integrity of the framework. From molecular modeling, the electronic structure of COK-69 was determined and a band gap of $3.77 \mathrm{eV}$ was found.
\end{abstract}

Metal-organic frameworks (MOFs) have been intensely studied over the past decade, with a vivid focus on creating more thermally and chemically robust materials that are highly desirable for numerous applications including catalysis, molecular separations and gas storage..$^{[1-5]}$ In this context, various research groups have reported frameworks based on the group IV elements, mainly $\mathrm{Zr}^{\mathrm{IV}}$ and $\mathrm{Hf}^{\mathrm{fl}}$. These oxophilic ions are known to yield clusters with a high connectivity, and the clusters are strongly coordinated by linker carboxylate groups to form robust

[*] B. Bueken, Dr. F. Vermoortele, Dr. H. Reinsch, Dr. P. Valvekens, Dr. T. De Baerdemaeker, Prof. Dr. R. Ameloot, Prof. Dr. C.E.A. Kirschhock, Prof. Dr. D. De Vos

Centre for Surface Chemistry and Catalysis, KU Leuven

Celestijnenlaan 200F, p.o. box 2461, 3001 Leuven, Belgium

E-mail: dirk.devos@biw.kuleuven.be

Dr. Dr. D.E.P. Vanpoucke, Prof. Dr. V. Van Speybroeck

Center for Molecular Modeling, Ghent University

Technologiepark 903, 9052 Zwijnaarde, Belgium

Dr. C.-C. Tsou, Prof. Dr. J.M. Mayer

Department of Chemistry, Yale University

225 Prospect Street, p.o. box 208107,

New Haven, CT 06511, USA

$[* *] \quad B B, P V, T D B, D E P V$, VVS and DDV gratefully acknowledge the FWO Flanders for funding (Aspirant grants, postdoctoral grant no $12 \mathrm{~S} 3415 \mathrm{~N}$, and grants G.0486.12, G.0959.13, G.0256.14). DDV thanks KULeuven for support through the Methusalem grant CASAS and IAP 7/05 Functional Supramolecular Systems. These authors are further grateful to the IWT for support (SBO-project MOFShape). VVS and DEPV acknowledge funding obtained by the Research Board of the Ghent University. CCT and JMM gratefully acknowledge a postdoctoral fellowship to CCT from the National Science Council of Taiwan and support from Yale University. The authors thank K. Houthoofd for NMR measurements, I. Cuppens for elemental analysis, T. Bosserez and W. Deleu for assistance with DRS and E. Brisse for editorial support. The computational resources were provided by the VSC, funded by Ghent University and the Hercules Foundation.

Supporting information for this article is given via a link at the end of the document.
MOFs. ${ }^{[6-13]}$ However, for titanium, very few crystalline threedimensional frameworks with guest-accessible porosity have been described. Despite the redox properties and photocatalytic potential associated with titanium, its low toxicity and the existence of numerous carboxylate-based Ti-clusters, ${ }^{[14,15]}$ the synthesis of Ti-carboxylate MOFs remains challenging. One notable exception is the $\mathrm{Ti}^{\mathrm{i} V}$-terephthalate MIL-125 and its variants, ${ }^{[16-18]}$ which can be synthesized either directly from Tilv butoxide or by use of a preformed octameric cluster. ${ }^{[19-21]}$

The prime hurdle in the synthesis of Ti-MOFs is the high reactivity of the commonly used Ti-precursors, which are susceptible to a fast olation and oxolation and thus readily form ill-defined oxyhydroxides. ${ }^{[15,22]}$ To partly overcome this issue, mixed-metal MOFs containing titanium have been synthesized, either by introducing $\mathrm{Ti}^{\mathrm{IV}}$ through post-synthetic metal exchange or by combining a Ti-precursor and a divalent metal salt during synthesis. ${ }^{[23-30]}$ Very recently, Zhou et al. used a hexanuclear Ticluster as metal source to form the porphyrinic Ti-MOF PCN$22 .{ }^{[31]}$ Interestingly, this preformed cluster rearranges during synthesis to form the final heptameric node found in the framework.

Here, we explore the use of a hydrolytically more robust organometallic Ti-precursor for the formation of porous $\mathrm{Ti}$ carboxylates. More specifically, by using dicyclopentadienyl titanium(IV) dichloride $\left(\mathrm{Cp}_{2} \mathrm{Ti}^{\mathrm{IV}} \mathrm{Cl}_{2}\right)$, we were able to synthesize COK-69, a new, breathing Tilv-trans-1,4cyclohexanedicarboxylate framework, which is among the few porous three-dimensional Ti MOFs reported to date. COK-69 contains a trinuclear $\left[\mathrm{Til}_{3}\left(\mu_{3}-\mathrm{O}\right)(\mathrm{O})_{2}(\mathrm{COO})_{6}\right]$ cluster not previously reported in MOFs. This cluster closely resembles analogous motifs based on trivalent cations that are encountered in several well-known MOFs such as MIL-88, MIL-96, MIL-100 and MIL-101. ${ }^{[32-36]}$ With the introduction of an analogous Ticluster in MOF chemistry, the road to the synthesis of a series of new structures with titanium is opened.

The reaction of $\mathrm{Cp}_{2} \mathrm{Ti}^{\mathrm{iV}} \mathrm{Cl}_{2}$ and trans-1,4-cyclohexanedicarboxylic acid $\left(\mathrm{H}_{2} \mathrm{Cdc}\right)$ in $\mathrm{N}, \mathrm{N}$-dimethylformamide (DMF), with acetic acid as synthesis modulator $\left(110^{\circ} \mathrm{C}, 48 \mathrm{~h}, \mathrm{Ar}\right.$ atmosphere) leads to the formation of a blue-grey colored microcrystalline solid, COK-69_R $(\mathrm{R}=$ reduced). Upon exposure to air, this solid rapidly transforms to the off-white COK-69 or $\left[\mathrm{Ti}_{3}{ }_{3}\left(\mu_{3}-\mathrm{O}\right)(\mathrm{O})_{2}(\mathrm{cdc})_{3} \cdot \mathrm{DMF}\right]_{\mathrm{n}}$. Using microwave irradiation $\left(220^{\circ} \mathrm{C}\right)$, the synthesis can be upscaled and synthesis time can be significantly reduced to $\sim 10$ minutes. Nevertheless, a higher quality material is obtained from the solvothermal reaction.

COK-69 contains trimeric $\mathrm{Ti}_{3}{ }_{3}\left(\mu_{3}-\mathrm{O}\right)$ secondary building units which are interconnected by six $\mathrm{cdc}^{2-}$ linkers to form a framework 


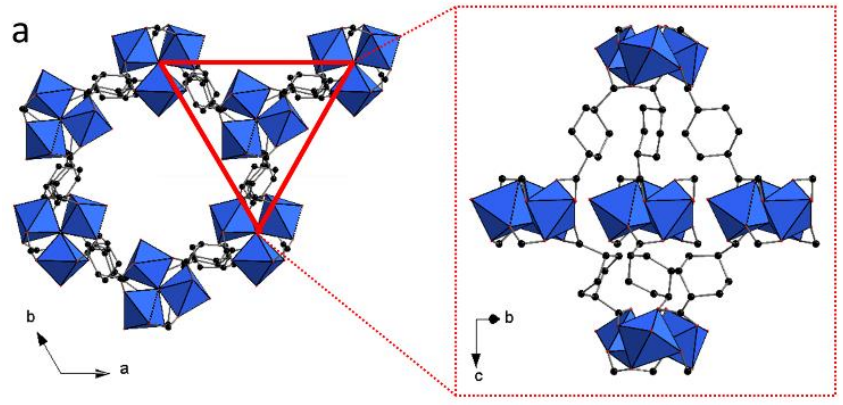

b

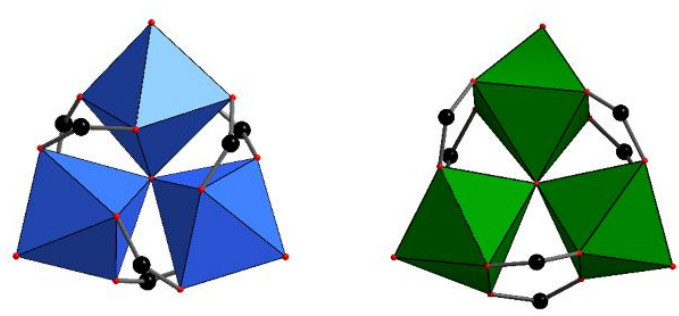

Figure 1. Structure of as-synthesized COK-69. a) 1-D hexagonal channels are constructed by stacking trigonal bipyramidal cages. b) $\left[\mathrm{Ti}^{\mathrm{IV}}{ }_{3} \mathrm{O}(\mathrm{O})_{2}\left(\mathrm{H}_{2} \mathrm{O}\right)(\mathrm{COO})_{6}\right]$ cluster (left) with tilted $\mathrm{TiO}_{6}$ octahedra (blue), as compared to the $\left[\mathrm{Cr}^{\mathrm{III}}{ }_{3} \mathrm{O}(\mathrm{Cl} / \mathrm{F})\left(\mathrm{H}_{2} \mathrm{O}\right)_{2}(\mathrm{COO})_{6}\right]$ cluster (right) from MIL-88; ${ }^{[36]} \mathrm{O}=$ red, $\mathrm{C}=$ black, $\mathrm{Cr}$ $=$ green.

with underlying acs-topology, featuring both trigonal bipyramidal cages and one-dimensional hexagonal channels (Figure 1, Figure S1-S4). This topology is the same as that of the well-known MIL88 family of materials. ${ }^{[36]}$ While MIL-88 and COK-69 contain similar trimeric clusters, the cyclohexanedicarboxylate linkers impose a tilt on the constituent $\mathrm{TiO}_{6}$ octahedra (Figure 1). From Rietveld refinement the central $\mu_{3}-\mathrm{O}$ atom was found to be located slightly above the plane defined by the Ti-ions (Figure S5).

Similar molecular Ti-clusters have previously been observed resulting from the solvolysis of $\mathrm{Cp}_{2} \mathrm{Ti}^{\mathrm{IV}} \mathrm{Cl}_{2}$, for example $\left[\mathrm{Ti}_{3}\left(\mu_{3^{-}}\right.\right.$ O) $\left.\left(\mu_{2}-\mathrm{OH}\right)_{3}\left(\mu_{2}-\mathrm{HCOO}\right)_{3}\left(\eta^{5}-\mathrm{Cp}\right)_{3}\right]^{+} \mathrm{HCOO}^{-[37-40]}$ Therefore, we assume that the synthesis of COK-69 proceeds via the in situ preformation of cyclopentadienyl-capped $\mathrm{Ti}_{3}\left(\mu_{3}-\mathrm{O}\right)$ clusters through the solvolysis of labile $\mathrm{Ti}^{\mathrm{IV}}-\mathrm{Cl}$ bonds. ${ }^{[41,42]}$ In the formation of these molecular species, the solvolytically more stable cyclopentadienyl ligands likely induce and direct cluster formation while shielding the titanium cations from fast and more extensive hydrolysis. ${ }^{[22,42]}$ The absence of oxide/hydroxide-impurities in COK-69 is supported by elemental analysis, yielding $21.6 \mathrm{wt} \% \mathrm{Ti}$ and $38 \mathrm{wt} \% \mathrm{C}$, which agrees well with the theoretical values of $20.5 \mathrm{wt} \%$ and $41.0 \mathrm{wt} \%$, respectively. Thermogravimetric analysis of COK-69 (Figure S7-S8) shows a first mass loss step between $100{ }^{\circ} \mathrm{C}$ and $225^{\circ} \mathrm{C}$ due to the loss of one DMF per cage $(8.8 \mathrm{wt} \%$, theoretical 9.4 wt\%), followed by slow framework decomposition between $240{ }^{\circ} \mathrm{C}$ and $530^{\circ} \mathrm{C}$. The residual mass of $\mathrm{TiO}_{2}, 30.7 \mathrm{wt} \%$, corresponds well to the calculated value of $31 \mathrm{wt} \%$. No cyclopentadienyl fragments are observed in COK-69 via solid state ${ }^{13} \mathrm{C}$-CP-MAS NMR or FTIR, indicating the complete removal of all of these ligands during solvothermal synthesis (Figures S9S10). The amount of residual $\mathrm{N}$ and $\mathrm{Cl}$ in evacuated COK-69 $\left(120^{\circ} \mathrm{C}\right.$ overnight in air) was found to be $<1 \mathrm{wt} \%$.
While the presence of the central $\mu_{3}-\mathrm{O}$ group is unambiguous from Rietveld refinement, the nature of the species occupying the apical position of each Ti octahedron $\left(\mathrm{OH}^{-}, \mathrm{O}^{2-}\right.$ or $\left.\mathrm{H}_{2} \mathrm{O}\right)$ cannot be determined directly from the diffraction data. Therefore, ab initio level periodic calculations were performed on the COK-69 structure, starting from a cluster with three apical oxo-groups (Figure S26a), as obtained from Rietveld refinement. The formation energies obtained after structure optimization show that charge neutrality can be achieved by removing one of the apical oxo groups from the cluster $\left(\sim-2.8 \mathrm{eV} /\right.$ cluster; $\left[\mathrm{Til}_{3}\left(\mu_{3}-\right.\right.$ $\mathrm{O})(\mathrm{O})_{2}(\mathrm{COO})_{6}$ ] in Figure S26e). However, the structure is stabilized even more ( -6.1 eV/cluster) by the addition of two $\mathrm{H}$ atoms, either with formation of two hydroxyl groups $\left(\left[\mathrm{Ti}^{\mathrm{IV}} \mathrm{B}_{3}\left(\mu_{3}-\right.\right.\right.$ $\left.\mathrm{O}) \mathrm{O}(\mathrm{OH})_{2}(\mathrm{COO})_{6}\right]$, COK-6920H $)$ or by forming a cluster-bound water molecule $\left(\left[\mathrm{TiV}_{3}\left(\mu_{3}-\mathrm{O}\right)(\mathrm{O})_{2}\left(\mathrm{H}_{2} \mathrm{O}\right)(\mathrm{COO})_{6}\right]\right.$, COK-69 $\left.{ }^{\mathrm{H} 2 \mathrm{O}}\right)$, as shown in Figure S26b-c. The small energy difference between COK-6920H and COK-69 ${ }^{\mathrm{H} 2 \mathrm{O}}$ (Table S4) indicates both structures are plausible. Under experimental conditions however, $\mathrm{H}^{+}$might hop from a hydroxyl group (Figure S26b) to another $\mathrm{OH}$ group to form a bound water molecule (Figure S26c), which could be lost upon thermal evacuation. Since no $\mathrm{OH}$ groups can be discerned in the FTIR spectrum of COK-69 (Figure S10), we suggest $\left[\mathrm{Til}_{3}\left(\mu_{3}-\mathrm{O}\right)(\mathrm{O})_{2}(\mathrm{cdc})_{3}\right]_{\mathrm{n}}$ and $\left[\mathrm{TiV}_{3}\left(\mu_{3}-\mathrm{O}\right)(\mathrm{O})_{2}\left(\mathrm{H}_{2} \mathrm{O}\right)(\mathrm{cdc})_{3}\right]_{\mathrm{n}}$ to be the likely formulae for the evacuated COK-69 material and that exposed to ambient conditions, respectively.

COK-69 shows an interesting and rare breathing behavior. ${ }^{[43-45]}$ Upon washing the as-synthesized compound with DMF and methanol followed by thermal evacuation, a structural change is observed due to the conformational flexibility of the $\mathrm{cdc}^{2-}$ linker. The cyclohexyl ring in the chair conformation allows the trans carboxylate groups on the 1- and 4-positions to adopt either the equatorial $e, e^{\prime}$ - or the axial $a, a^{\prime}$-conformation. In the assynthesized material where the pores are occupied by DMF, half of the $\mathrm{cdc}^{2-}$ linkers adopt the $a$, $a^{\prime}$-conformation while the other half assumes the elongated e,e'-form (Figure 2, right; Figure S11). Upon guest removal all linkers are observed to adopt the kinked a, $a^{\prime}$-conformation (Figure 2, left), which is confirmed by ${ }^{13} \mathrm{C}-\mathrm{NMR}$ (Figure S9). Concomitantly, the framework drastically shrinks with a reduction of the unit cell volume by $21 \%$ and a shift in peak positions and intensities in the powder X-ray diffractograms (Figure 2).

Immersion of the closed-pore solid (COK-69 9 ) in solvents of low polarity such as toluene or tetrahydrofuran at $70^{\circ} \mathrm{C}$ results in the complete recovery of the open-pore solid (COK-69op), with a diffraction pattern identical to that of the as-synthesized material. On the other hand, polar solvents such as acetonitrile or dimethylsulfoxide are incapable of reopening the evacuated material (Figure S12). Furthermore, the presence of hydrogen bond donating groups seems to be generally unfavorable to induce a recovery of COK-69 op. This is illustrated by 2-butanol, which does not open COK-69 $\mathrm{cp}$, while butanone does. Finally, molecular shape and size of the solvent appear to be crucial. Whereas toluene induces pore opening, ortho-xylene does not. A similar guest-induced breathing mechanism was recently reported for the MIL-53 analogue $[\mathrm{M}(\mathrm{OH})(\mathrm{cdc})]$ or $\mathrm{CAU}-13(\mathrm{M}=$ $\mathrm{Al}, \mathrm{Ga}) .{ }^{[46-48]}$ On the other hand, the breathing behavior of COK69 is distinctly different from that of its topological analogue MIL$88 \mathrm{~B}$ which contains rigid terephthalate linkers. ${ }^{[49]}$ The flexibility of MIL-88 type materials arises from rotation of the rigid linkers 


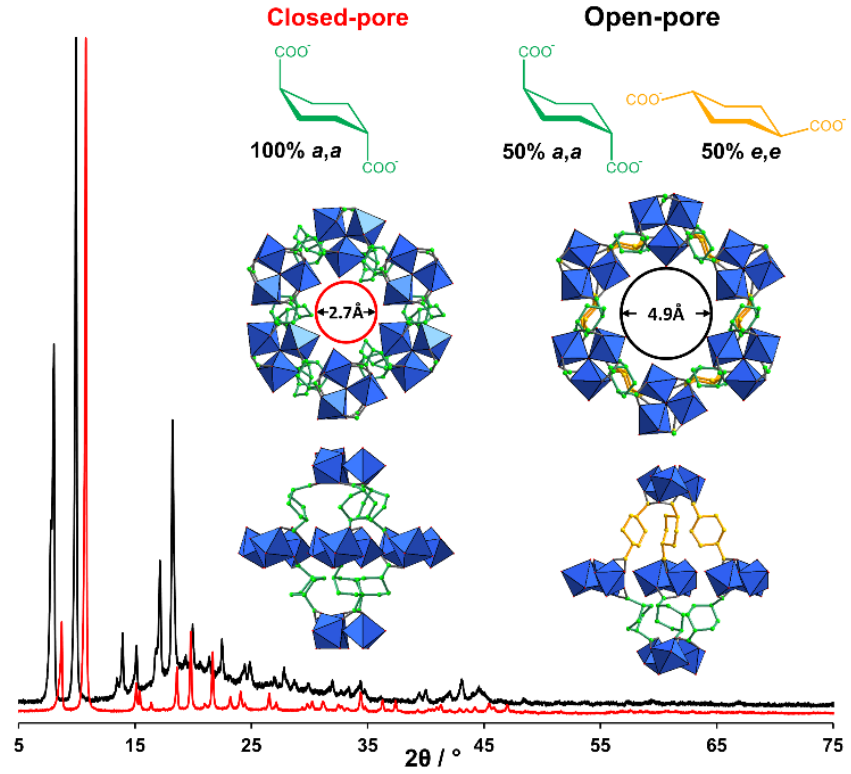

Figure 2. Powder X-ray diffraction patterns and structures of COK-69 $9_{\mathrm{cp}}$ (red; left) and COK-69op (black; right). COK-69 op consists of cdc $^{2-}$ linkers in both the $e, e^{\prime}-$ (yellow) and a,a'-conformation (green) in a $1 / 1$ ratio, while COK-69 $\mathrm{cp}$ contains solely $a, a^{\prime}-c^{2} c^{2-}$. Guests omitted for clarity.

around the axis through the oxygen atoms of each carboxylate group (the so-called 'knee cap' mechanism, Figure S13), ${ }^{[43]}$ whereas for COK-69, breathing is a consequence of the inherent flexibility of the linker itself.

Due to the contraction of the COK-69 framework upon evacuation, the diameter of the one-dimensional channels changes from 4.9 $\AA$ in the open form to $2.7 \AA$ in the closed-pore system (Figure 2). As a result, the porosity of COK- $69_{\text {cp }}$ for $\mathrm{N}_{2}$ is rather limited, with a BET surface area of $29.1 \mathrm{~m}^{2} \cdot \mathrm{g}^{-1}$ (Figure S14). Because it is impossible to determine the porosity of the guest-loaded COK$69_{\mathrm{op}}$ via gas adsorption, the void volume of the framework was estimated to be $37.3 \%$ using the Mercury software $\left(\mathrm{N}_{2}\right.$ probe radius $1.82 \AA$; grid $0.1 \AA$ ). ${ }^{[50]}$ For COK- $69_{\text {cp }}$, a similar calculation finds a void volume of $10.5 \%$; however due to the framework contraction this void space is located in isolated pockets rather than in continuous one-dimensional channels (Figure S15-S16). An important incentive for the development of Ti-based MOFs is their expected photoactivity and potential redox behavior. In the case of COK-69, the formation of a blue colored solid during synthesis already strongly hints at the presence of Till'-species, possibly formed by reduction of $\mathrm{Ti}^{\mathrm{IV}}$ with DMF. ${ }^{[16,51]}$ The diffuse reflectance UV-Vis spectrum of air-exposed COK-69 samples (Figure S17) reveals a strong absorption in the 200-350 nm region, with a maximum around $314 \mathrm{~nm}$. From molecular modeling, the electronic structures of some of the relevant models for COK-69 were determined (Figure 3). For COK-6920H and COK-69 ${ }^{\mathrm{H} 2 \mathrm{O}}$, a band gap of 3.42 and $3.77 \mathrm{eV}$ was determined respectively, which is in fair agreement with the observed absorption spectrum (Table S4 \& Figure S17). The conduction band is made up of Ti states (cyan curves), as is also seen in other MOFs. ${ }^{[52]}$ The $\mathrm{H}$ atoms present on the Ti-clusters only have contributions deep inside the valence bands (pink curves), not modifying the electronic structure around the band gap.
Irradiation of COK-69 in ethanol using a UV-A $(\lambda=315-400 \mathrm{~nm})$ light source readily affords a blue solid, COK-69_R (Figure 4a). This reduced material displays a broad absorption extending into the near infrared (Figure S18). The electron paramagnetic resonance (EPR) spectrum of COK-69_R shows a clear signal with fitted $g$-parameters $g_{\|} \approx 1.914$, and $g_{\perp} \approx 1.954$ (Figure $4 b$ ) which corresponds to a Till'-species in a distorted octahedral environment. ${ }^{[16,53]}$ The photoreduced material does not show any loss in crystallinity (Figure S19), which signifies that the $\left[\mathrm{Ti}_{3}\left(\mu_{3}\right.\right.$ $\mathrm{O})(\mathrm{O})_{2}(\mathrm{COO})_{6}$ ] cluster can accommodate changes in titanium valence without the framework collapsing or undergoing a phase change. From charge balance considerations however, the reduction of a Tilv to Till should be accompanied by the introduction of an additional positive charge. The photoreduction mechanism thus most likely involves the transformation of an oxogroup, e.g. in a titanyl group, to a hydroxyl group. To assess the plausibility of such a reduction, a hypothetical structure with three apical $\mathrm{OH}$ groups (COK-69 ${ }^{3 \mathrm{OH}}$; Figure $\mathrm{S} 26 \mathrm{~g}$ ) was modeled, which was found to be even more stable than $\mathrm{COK}-69^{2 \mathrm{OH}}$ and COK$69^{\mathrm{H} 2 \mathrm{O}}$. Hirshfeld-I charges show the $\mathrm{Ti}$ atoms in a single cluster to be differentiated as two $\mathrm{Ti}^{\mathrm{IV}}$ atoms and one $\mathrm{Ti}^{\mathrm{III}}$ atom, with charges of 2.87 and $2.49 \mathrm{e}$, respectively, ${ }^{[54,55]}$ in accordance with the EPR observation of a Ti"l-species. The calculated electronic structure of COK-69 ${ }^{3 \mathrm{OH}}$ (Figure 3) shows a semi-conducting band gap upon reduction, comparable to that of $\mathrm{Si}$ in size, in agreement with the experimental absorption spectrum.

To further confirm the formation of hydroxyl groups, an experiment was undertaken using $\mathrm{C}_{2} \mathrm{H}_{5} \mathrm{OD}$ as a reductant. ${ }^{2} \mathrm{H}$ MAS-NMR showed the absence of deuterated hydroxyl groups prior to photoreduction. After irradiation and removal of residual $\mathrm{C}_{2} \mathrm{H}_{5} \mathrm{OD}$, a distinct signal at $7.1 \mathrm{ppm}$ is observed in the ${ }^{2} \mathrm{H}-\mathrm{NMR}$ spectrum of COK-69_R (Figure 4c), which can be attributed to the

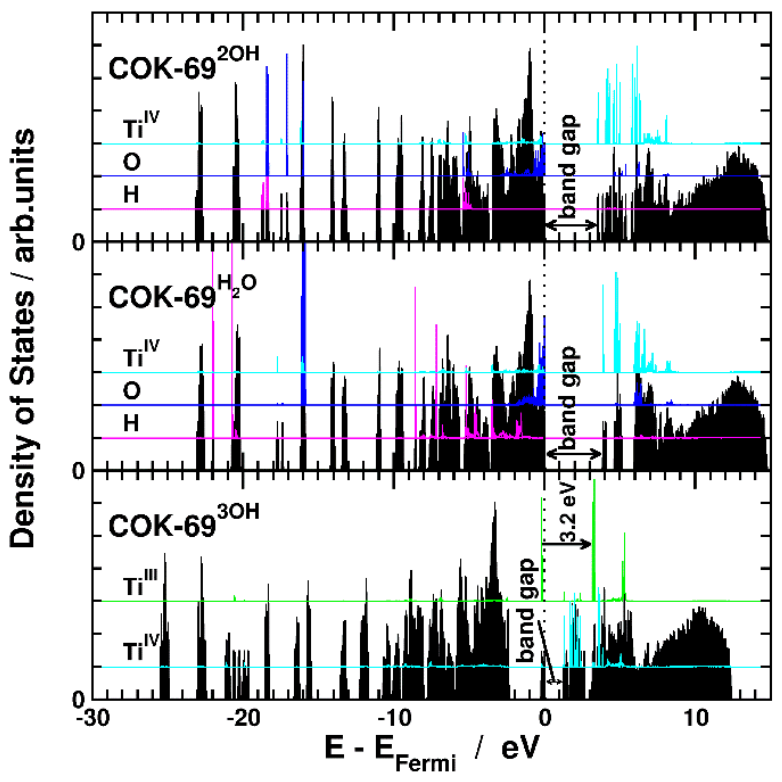

Figure 3. Calculated total Density of States (DOS; black curves), using the HSE06 functional[56] for COK-69 ${ }^{2 \mathrm{OH}}$ (top), COK-69 ${ }^{\mathrm{H} 2 \mathrm{O}}$ (middle) and COK-69 ${ }^{3 \mathrm{OH}}$ (bottom). The site projected DOS of relevant atoms are indicated as offset curves: $\mu_{3}-\mathrm{O} \& \mathrm{O}$ (blue), $\mathrm{H}$ (pink), $\mathrm{Ti}^{\mathrm{IV}}$ (cyan) and $\mathrm{Ti}^{\mathrm{ill}}$ (green). The dashed line indicates the Fermi level, while the band gap is indicated with a double arrow. The excitation of $\mathrm{Ti}^{\mathrm{III}}$ in COK-69 $\mathrm{C}^{3 \mathrm{OH}}$ is indicated with an arrow. 


\section{a}
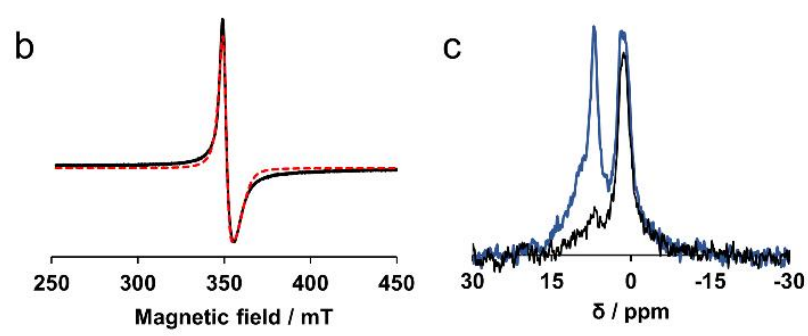

d

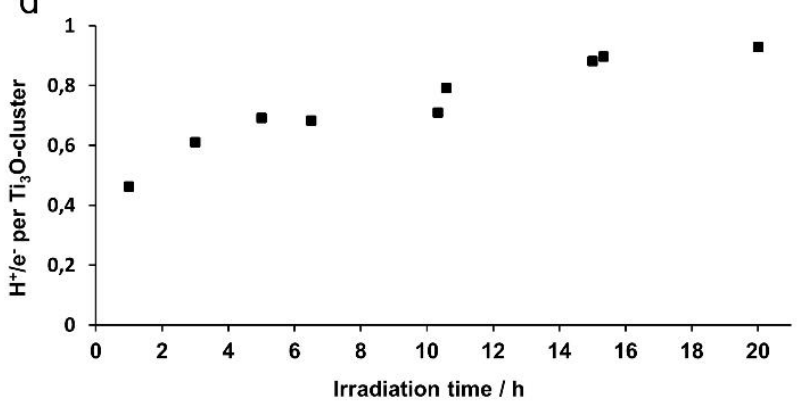

Figure 4. Photoreduction of COK-69; a) COK-69 (white, top) and COK-69_R (blue, bottom); b) EPR spectrum ( $296 \mathrm{~K}$ ) after photoreduction indicating the presence of a Till species with parameters $g_{/ /} \approx 1.914$, and $g_{\perp} \approx 1.954$ (red $=$ simulated); c) ${ }^{2} \mathrm{H}-\mathrm{MAS}$ NMR after photoreduction (blue) with $\mathrm{C}_{2} \mathrm{H}_{5} \mathrm{OD}$ as reductant and subsequent re-oxidation (black). The signal at $7.1 \mathrm{ppm}$ is ascribed to a Ti-OD species; d) PCET from COK-69_R to tBu$_{3} A \mathrm{ArO}^{\circ}$ (44 $\mathrm{h}$ reaction) as a function of UV irradiation time for COK-69 in ethanol.

formation of Ti-OD groups. Upon exposure to air, this signal disappears again due to oxidation of the Till' cation and the concomitant reformation of an oxo-group. The signal at $1.5 \mathrm{ppm}$ is ascribed to naturally abundant deuterium on the cdc $^{2-}$ linker. These observations confirm that the photoreduction and reoxidation of COK-69 involve the simultaneous transfer of both an electron and a proton. Such proton-coupled electron transfer (PCET) has previously also been found for $\mathrm{ZnO}$ and $\mathrm{TiO}_{2}$ nanoparticles upon UV irradiation and subsequent reoxidation with phenoxy or nitroxy radicals. ${ }^{[57]}$ In order to quantify the maximum number of formed Till centers in COK-69_R, PCET experiments were conducted at different UV-A irradiation times, whereby the amounts of $\mathrm{e}^{-}$and $\mathrm{H}^{+}$transferred from COK-69_R to the 2,4,6-tri-tert-butylphenoxy radical $\left(t \mathrm{Bu}_{3} \mathrm{ArO}^{*}\right)$ in $\mathrm{C}_{6} \mathrm{D}_{6}$ were followed via ${ }^{1} \mathrm{H}-\mathrm{NMR}$ (Figure $4 \mathrm{~d}$ and $\mathrm{S} 20-24$ ). The results of these experiments indicate that up to one third of all $\mathrm{Ti}^{\mathrm{il}}$, i.e. one per $\mathrm{Ti}_{3}$ cluster, can be reduced, which is in accordance with the charges calculated for $\mathrm{COK}-69^{3 \mathrm{OH}}$. Thus, even in the closed-pore form, essentially all clusters are able to participate in the photoreduction. Based on these PCET experiments, the empirical formula $\left[\mathrm{Ti}_{3}{ }_{3}\right.$ $\left.{ }_{x} \mathrm{Ti}^{\mathrm{III}}{ }_{x}\left(\mu_{3}-\mathrm{O}\right)(\mathrm{OH})_{x}(\mathrm{O})_{2-x}(\mathrm{cdc})_{3}\right]_{\mathrm{n}}$ is proposed for COK-69_R $(x=0-1)$. The fraction of reduced $\mathrm{Ti}$ strongly depends on the applied irradiation time. The reaction between $\mathrm{tBu}_{3} \mathrm{ArO} \mathrm{O}^{\circ}$ and $\mathrm{COK}-69 \mathrm{R}$ is only complete after prolonged contact times. No significant difference in reduction rate was observed between COK-69 $9_{\mathrm{cp}}$ and COK-69 $9_{\text {op }}$, as evidenced by EPR measurements (Figure S25). This indicates that there is an efficient transport of both electrons and protons to and from the particle surface when the material is exposed to either reductants (e.g. ethanol) or oxidants (e.g. $\mathrm{O}_{2}$ ). In conclusion, we developed a new synthetic route for titanium metal-organic frameworks by employing titanocene dichloride as the metal source. This allows a more precise control over the solvolysis of the metal precursor, ultimately leading to the formation of COK-69, the first flexible Ti-MOF featuring a photoactive trinuclear cluster. We expect that through this discovery, the road will be opened to synthesizing a much more diverse library of photoactive Ti-MOFs, including well-known topologies such as MIL-100 and MIL-101. Furthermore, the use of other metallocenes (e.g. of $\mathrm{Zr}^{\mathrm{IV}}, \mathrm{Hf}^{\mathrm{IV}}, \mathrm{V}^{\mathrm{IV}}, \mathrm{Mo}^{\mathrm{IV}}, \mathrm{Ta}^{\mathrm{V}}$ ) in MOF synthesis holds great promise for the discovery of previously unattainable topologies.

\section{Experimental and Computational Section}

All chemicals used were commercially obtained and used without further purification. In a typical synthesis, $0.5 \mathrm{mmol}$ of $\mathrm{Cp}_{2} \mathrm{Ti}^{\mathrm{I}} \mathrm{Cl}_{2}$ and $1 \mathrm{mmol}$ of $\mathrm{H}_{2} \mathrm{cdc}$ are dissolved in $5 \mathrm{ml}$ DMF together with $1.73 \mathrm{mmol}$ of glacial acetic acid, and the mixture was transferred to a glass reactor and allowed to react at $110^{\circ} \mathrm{C}(48 \mathrm{~h})$. The formed white precipitate (COK-69) is extensively washed with DMF and methanol and evacuated overnight at $120^{\circ} \mathrm{C}$ in air. To obtain COK-69_R after synthesis, the reactor was flushed with Ar prior to reaction. CCDC 1406339-1406340 contain the supplementary crystallographic data for this work. These data can be obtained free of charge from The Cambridge Crystallographic Data Centre via www.ccdc.cam.ac.uk/data_request/cif. Full experimental details, including characterization, structure solution, photoreduction and PCET procedures can be found in the supporting information. All theoretical calculations were performed using the Density Functional Theory formalism within the projector augmented wave (PAW) method as implemented in the VASP program. ${ }^{[58,59]}$ CCDC 1063991-1063994 contain the supplementary modeled crystallographic data structures for this paper. Full computational details can be found in the supporting information.

Keywords: titanium $\bullet$ metal-organic frameworks $\cdot$ metallocenes - molecular modeling $\cdot$ photochemistry

[1] J.-R. Li, J. Sculley, H.-C. Zhou, Chem. Rev. 2012, 112, 869-932. [2] H. Furukawa, K. E. Cordova, M. O'Keeffe, O. M. Yaghi, Science 2013, 341, 1230444.

[3] P. Valvekens, F. Vermoortele, D. De Vos, Catal. Sci. Technol. 2013 3, 1435.

[4] J. Liu, L. Chen, H. Cui, J. Zhang, L. Zhang, C.-Y. Su, Chem. Soc. Rev. 2014, 43, 6011-6061.

[5] B. Van de Voorde, B. Bueken, J. Denayer, D. De Vos, Chem. Soc Rev. 2014, 43, 5766-88.

[6] J. H. Cavka, S. Jakobsen, U. Olsbye, N. Guillou, C. Lamberti, S. Bordiga, K. P. Lillerud, J. Am. Chem. Soc. 2008, 130, 13850-1.

[7] V. Guillerm, F. Ragon, M. Dan-Hardi, T. Devic, M. Vishnuvarthan, B. Campo, A. Vimont, G. Clet, Q. Yang, G. Maurin, et al., Angew. Chem. Int. Ed. Engl. 2012, 51, 9267-71.

[8] V. Bon, I. Senkovska, M. S. Weiss, S. Kaskel, CrystEngComm 2013, 15, 9572.

[9] D. Feng, H.-L. Jiang, Y.-P. Chen, Z.-Y. Gu, Z. Wei, H.-C. Zhou, Inorg. Chem. 2013, 52, 12661-7.

[10] M. H. Beyzavi, R. C. Klet, S. Tussupbayev, J. Borycz, N. A. Vermeulen, C. J. Cramer, J. F. Stoddart, J. T. Hupp, O. K. Farha, J. Am. Chem. Soc. 2014, 136, 15861-4.

[11] H. Furukawa, F. Gándara, Y.-B. Zhang, J. Jiang, W. L. Queen, M. R. Hudson, O. M. Yaghi, J. Am. Chem. Soc. 2014, 136, 4369-81.

[12] H. Reinsch, I. Stassen, B. Bueken, A. Lieb, R. Ameloot, D. De Vos, CrystEngComm 2014, 17, 331-337.

[13] T.-F. Liu, D. Feng, Y.-P. Chen, L. Zou, M. Bosch, S. Yuan, Z. Wei S. Fordham, K. Wang, H.-C. Zhou, J. Am. Chem. Soc. 2015, 137, 413-419. 
[14] L. Rozes, N. Steunou, G. Fornasieri, C. Sanchez, Monatshefte für Chemie - Chem. Mon. 2006, 137, 501-528.

[15] L. Rozes, C. Sanchez, Chem. Soc. Rev. 2011, 40, 1006-30.

[16] M. Dan-Hardi, C. Serre, T. Frot, L. Rozes, G. Maurin, C. Sanchez, G. Férey, J. Am. Chem. Soc. 2009, 131, 10857-9.

[17] C. Zlotea, D. Phanon, M. Mazaj, D. Heurtaux, V. Guillerm, C. Serre P. Horcajada, T. Devic, E. Magnier, F. Cuevas, et al., Dalton Trans. 2011, 40, 4879-81.

[18] J. H. Im, N. Ko, S. J. Yang, H. J. Park, J. Kim, C. R. Park, New J. Chem. 2014, 38, 2752

[19] H. Barrow, D. A. Brown, N. W. Alcock, H. J. Clase, M. G. H. Wallbridge, J. Chem. Soc. Chem. Commun. 1995, 1231.

[20] P. Piszczek, M. Richert, A. Grodzicki, T. Głowiak, A. Wojtczak, Polyhedron 2005, 24, 663-670.

[21] T. Frot, S. Cochet, G. Laurent, C. Sassoye, M. Popall, C. Sanchez, L. Rozes, Eur. J. Inorg. Chem. 2010, 2010, 5650-5659.

[22] T. Devic, C. Serre, Chem. Soc. Rev. 2014, 43, 6097-115.

[23] W. Xuan, C. Ye, M. Zhang, Z. Chen, Y. Cui, Chem. Sci. 2013, 4 3154.

[24] K. Hong, H. Chun, Chem. Commun. 2013, 49, 10953-5.

[25] K. Hong, W. Bak, H. Chun, Inorg. Chem. 2013, 52, 5645-7.

[26] K. Hong, W. Bak, D. Moon, H. Chun, Cryst. Growth Des. 2013, 13 4066-4070.

[27] C. H. Lau, R. Babarao, M. R. Hill, Chem. Commun. 2013, 49, 36346.

C. Zhu, X. Chen, Z. Yang, X. Du, Y. Liu, Y. Cui, Chem. Commun. 2013, 49, 7120-2.

C. K. Brozek, M. Dincă, J. Am. Chem. Soc. 2013, 135, 12886-91. D. Sun, W. Liu, M. Qiu, Y. Zhang, Z. Li, Chem. Commun. 2015, 51, 2056-2059.

S. Yuan, T.-F. Liu, D. Feng, J. Tian, K. Wang, J. Qin, Q. ZHANG, Y.-P. Chen, M. Bosch, L. Zou, et al., Chem. Sci. 2015, DOI 10.1039/C5SC00916B

G. Férey, C. Serre, C. Mellot-Draznieks, F. Millange, S. Surblé, J. Dutour, I. Margiolaki, Angew. Chemie 2004, 116, 6456-6461. C. Serre, F. Millange, S. Surblé, G. Férey, Angew. Chem. Int. Ed. Engl. 2004, 43, 6285-9.

G. Férey, C. Mellot-Draznieks, C. Serre, F. Millange, J. Dutour, S. Surblé, I. Margiolaki, Science 2005, 309, 2040-2

T. Loiseau, L. Lecroq, C. Volkringer, J. Marrot, G. Férey, M. Haouas, F. Taulelle, S. Bourrelly, P. L. Llewellyn, M. Latroche, J. Am. Chem. Soc. 2006, 128, 10223-30.

[36] S. Surblé, C. Serre, C. Mellot-Draznieks, F. Millange, G. Férey, Chem. Commun. 2006, 284-6.

[37] H. Köpf, S. Grabowski, R. Voigtländer, J. Organomet. Chem. 1981, 216, 185-190.
H. Aslan, T. Sielisch, R. Dieter Fischer, J. Organomet. Chem. 1986 315, C69-C72.

[39] K. Doppert, U. Thewalt, J. Organomet. Chem. 1986, 301, 41-48.

[40] T. C. Stamatatos, S. P. Perlepes, M. J. Manos, A. J. Tasiopoulos, N. Klouras, J. Coord. Chem. 2011, 64, 2377-2387.

[41] J. H. Toney, T. J. Marks, J. Am. Chem. Soc. 1985, 107, 947-953.

[42] T. Maschmeyer, F. Rey, G. Sankar, J. M. Thomas, Nature 1995 378, 159-162.

[43] G. Férey, C. Serre, Chem. Soc. Rev. 2009, 38, 1380-99.

[44] S. Horike, S. Shimomura, S. Kitagawa, Nat. Chem. 2009, 1, 695704.

[45] H. Sato, W. Kosaka, R. Matsuda, A. Hori, Y. Hijikata, R. V Belosludov, S. Sakaki, M. Takata, S. Kitagawa, Science 2014, 343 , 167-70.

[46] F. Niekiel, M. Ackermann, P. Guerrier, A. Rothkirch, N. Stock, Inorg Chem. 2013, 52, 8699-705.

[47] H. Reinsch, D. De Vos, Microporous Mesoporous Mater. 2014, 200 , 311-316.

[48] F. Niekiel, J. Lannoeye, H. Reinsch, A. S. Munn, A. Heerwig, I. Zizak, S. Kaskel, R. I. Walton, D. de Vos, P. Llewellyn, et al., Inorg. Chem. 2014, 53, 4610-20.

[49] C. Serre, C. Mellot-Draznieks, S. Surblé, N. Audebrand, Y. Filinchuk, G. Férey, Science 2007, 315, 1828-31.

[50] C. F. Macrae, I. J. Bruno, J. A. Chisholm, P. R. Edgington, P. McCabe, E. Pidcock, L. Rodriguez-Monge, R. Taylor, J. van de Streek, P. A. Wood, J. Appl. Crystallogr. 2008, 41, 466-470.

[51] V. M. Khomenko, K. Langer, H. Rager, A. Fett, Phys. Chem. Miner. 1998, 25, 338-346.

[52] D. E. P. Vanpoucke, J. W. Jaeken, S. De Baerdemacker, K Lejaeghere, V. Van Speybroeck, Beilstein J. Nanotechnol. 2014, 5, 1738-48.

[53] N. M. Dimitrijevic, Z. V. Saponjic, B. M. Rabatic, O. G. Poluektov, T. Rajh, J. Phys. Chem. C 2007, 111, 14597-14601.

[54] D. E. P. Vanpoucke, P. Bultinck, I. Van Driessche, J. Comput. Chem. 2013, 34, 405-17.

[55] D. E. P. Vanpoucke, I. Van Driessche, P. Bultinck, J. Comput. Chem. 2013, 34, 422-7.

[56] J. Heyd, G. E. Scuseria, M. Ernzerhof, J. Chem. Phys. 2003, 118, 8207.

[57] J. N. Schrauben, R. Hayoun, C. N. Valdez, M. Braten, L. Fridley, J. M. Mayer, Science 2012, 336, 1298-301.

[58] G. Kresse, J. Hafner, Phys. Rev. B 1993, 47, 558-561.

[59] G. Kresse, Phys. Rev. B 1999, 59, 1758-1775. 


\section{COMMUNICATION}

An innovative synthetic approach to titanium-based metal-organic frameworks (MOFs) using titanocene dichloride leads to COK-69, the first breathing Ti-MOF built up of trans-1,4cyclohexanedicarboxylate and an unprecedented, photoactive $\left[\mathrm{TiV}_{3}\left(\mu_{3^{-}}\right.\right.$ $\left.\mathrm{O})(\mathrm{COO})_{6}\right]$ inorganic building unit.

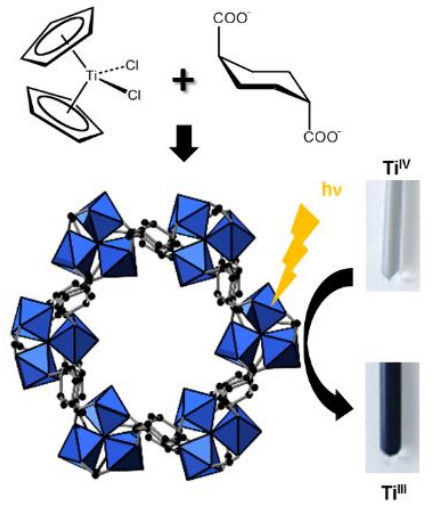

Bart Bueken, Dr. Frederik Vermoortele, Dr. Dr. Danny E. P. Vanpoucke, Dr. Helge Reinsch, Dr. Chih-Chin Tsou, Dr Pieterjan Valvekens, Dr. Trees De Baerdemaeker, Prof. Dr. Rob Ameloot, Prof. Dr. Christine E. A. Kirschhock, Prof. Dr. Veronique Van Speybroeck, Prof. Dr. James M. Mayer and Prof. Dr. Dirk De Vos*

Page No. - Page No.

A Flexible Photoactive Titanium Metal-Organic Framework Based on a $\left[\mathrm{TiV}_{3}\left(\mu_{3}-\mathrm{O}\right)(\mathrm{COO})_{6}\right]$ Cluster

As published in Angewandte Chemie, International Edition, vol. 54 (47), p. 13912-13917, doi: 10.1002/anie.201505512.

(C) 2015, Wiley-VCH Verlag GmbH \& Co. KGaA, Weinheim 